Check for updates

Cite this: Chem. Sci., 2020, 11, 11801

๑ All publication charges for this article have been paid for by the Royal Society of Chemistry
Received 10th July 2020 Accepted 2nd October 2020

DOI: $10.1039 / \mathrm{dOsc03787g}$

rsc.li/chemical-science

\section{Single-ion magnetism in the extended solid-state: insights from X-ray absorption and emission spectroscopy $\dagger$}

\author{
Myron S. Huzan, (D) ab Manuel Fix, ${ }^{c}$ Matteo Aramini, ${ }^{d}$ Peter Bencok, ${ }^{d}$ \\ J. Frederick W. Mosselmans, (D)d Shusaku Hayama, ${ }^{d}$ Franziska A. Breitner, ${ }^{c}$ \\ Leland B. Gee, (D) e Charles J. Titus, (D) ${ }^{f}$ Marie-Anne Arrio, ${ }^{g}$ Anton Jesche ${ }^{c}$ \\ and Michael L. Baker (D)*ab
}

\begin{abstract}
Large single-ion magnetic anisotropy is observed in lithium nitride doped with iron. The iron sites are twocoordinate, putting iron doped lithium nitride amongst a growing number of two coordinate transition metal single-ion magnets (SIMs). Uniquely, the relaxation times to magnetisation reversal are over two orders of magnitude longer in iron doped lithium nitride than other $3 \mathrm{~d}$-metal SIMs, and comparable with high-performance lanthanide-based SIMs. To understand the origin of these enhanced magnetic properties a detailed characterisation of electronic structure is presented. Access to dopant electronic structure calls for atomic specific techniques, hence a combination of detailed single-crystal X-ray absorption and emission spectroscopies are applied. Together $\mathrm{K}$-edge, $\mathrm{L}_{2,3}$-edge and $\mathrm{K} \beta \mathrm{X}$-ray spectroscopies probe local geometry and electronic structure, identifying iron doped lithium nitride to be a prototype, solid-state SIM, clean of stoichiometric vacancies where Fe lattice sites are geometrically equivalent. Extended $\mathrm{X}$-ray absorption fine structure and angular dependent single-crystal $\mathrm{X}$-ray absorption near edge spectroscopy measurements determine Fe' dopant ions to be linearly coordinated, occupying a $D_{6 \mathrm{~h}}$ symmetry pocket. The dopant engages in strong $3 \mathrm{~d} \pi$-bonding, resulting in an exceptionally short $\mathrm{Fe}-\mathrm{N}$ bond length $(1.873(7) \AA \AA)$ and rigorous linearity. It is proposed that this structure protects dopant sites from Renner-Teller vibronic coupling and pseudo Jahn-Teller distortions, enhancing magnetic properties with respect to molecular-based linear complexes. The Fe ligand field is quantified by $L_{2,3}$-edge XAS from which the energy reduction of $3 \mathrm{~d}_{z^{2}}$ due to strong $4 \mathrm{~s}$ mixing is deduced. Quantification of magnetic anisotropy barriers in low concentration dopant sites is inhibited by many established methods, including far-infrared and neutron scattering. We deduce variable temperature $\mathrm{L}_{3}$ edge XAS can be applied to quantify the $J=7 / 2$ magnetic anisotropy barrier, $34.80 \mathrm{meV}\left(\sim 280 \mathrm{~cm}^{-1}\right)$, that corresponds with Orbach relaxation via the first excited, $M_{J}= \pm 5 / 2$ doublet. The results demonstrate that dopant sites within solid-state host lattices could offer a viable alternative to rare-earth bulk magnets and high-performance SIMs, where the host matrix can be tailored to impose high symmetry and control lattice induced relaxation effects.
\end{abstract}

\section{Introduction}

${ }^{a}$ The University of Manchester at Harwell, Diamond Light Source, Harwell Campus, OX11 ODE, UK. E-mail: michael.baker@manchester.ac.uk

${ }^{b}$ Department of Chemistry, The University of Manchester, Manchester, M13 9PL, UK ${ }^{c} E P$ VI, Center for Electronic Correlations and Magnetism, Institute of Physics, University of Augsburg, D-86159 Augsburg, Germany

${ }^{d}$ Diamond Light Source, Harwell Science and Innovation Campus, Chilton, Didcot, OX11 ODE, UK

${ }^{e}$ Department of Chemistry, Stanford University, Stanford, CA 94305, USA

${ }^{f}$ Department of Physics, Stanford University, Stanford, CA 94305, USA

${ }^{g}$ Institut de Minéralogie, de Physique des Matériaux et de Cosmochimie, CNRS, Sorbonne Université, IRD, MNHN, UMR7590, 75252 Paris Cedex 05, France

$\dagger$ Electronic supplementary information (ESI) available. See DOI: $10.1039 / \mathrm{d} 0 \mathrm{sc} 03787 \mathrm{~g}$
Linearly coordinated transition metal ions can exhibit firstorder spin-orbit coupling which gives rise to large magnetic anisotropy barriers and bi-stability of magnetisation. An example of this is Fe doped in lithium nitride $\left(\mathrm{Li}_{2}\left(\mathrm{Li}_{1-x} \mathrm{Fe}_{x}\right) \mathrm{N}\right)$. The magnetic anisotropy energy of $\mathrm{Li}_{2}\left(\mathrm{Li}_{1-x} \mathrm{Fe}_{x}\right) \mathrm{N}$ exhibits an observed coercivity field of more than $11 \mathrm{~T}$, exceeding even the largest values observed in rare-earth-based permanent magnets. ${ }^{1}$ Consequently, the underlying electronic structure of $\mathrm{Li}_{2}\left(\mathrm{Li}_{1-x} \mathrm{Fe}_{x}\right) \mathrm{N}$ is of relevance to the search for alternatives to rare-earth materials. Furthermore, since large single-crystals can be prepared, ${ }^{2}$ and the concentration of Fe sites $(x)$ can be controlled, $\mathrm{Li}_{2}\left(\mathrm{Li}_{1-x} \mathrm{Fe}_{x}\right) \mathrm{N}$ prepared at low doping 
concentrations is proposed as single-ion like and therefore a solid-state equivalent ${ }^{3}$ to molecular based single ion magnets (SIMs). SIMs are complexes which display slow magnetic relaxation, and magnetic remanence relevant to nano-scale information storage technologies. Notable recent examples of linearly coordinated transition metal SIMs include a $\mathrm{Co}^{\mathrm{II}}\left(\mathrm{C}\left(\mathrm{SiMe}_{2} \mathrm{ONaph}\right)_{3}\right)_{2}$ (where naph is a naphthyl group) complex with a non-aufbau $\left(\mathrm{d}_{x^{2}-y^{2}}, \mathrm{~d}_{x y}\right)^{3}\left(\mathrm{~d}_{x z}, \mathrm{~d}_{y z}\right)^{3}\left(\mathrm{~d}_{z^{2}}\right)^{1}$ configuration and resultant $L=3$ ground-state orbital angular momentum. ${ }^{4}$ Another intriguing result are unusual $3 \mathrm{~d}$ ligand fields. A $D_{\infty \mathrm{h}}$ crystal field transforms the $3 \mathrm{~d}$-orbitals to a $\mathrm{A}_{1}\left(3 \mathrm{~d}_{z^{2}}\right)$ singlet at highest energy, followed by a $\mathrm{E}_{1 \mathrm{~g}}\left(3 \mathrm{~d}_{x z}, 3 \mathrm{~d}_{y z}\right)$ doublet at an intermediate energy and a $\mathrm{E}_{2 \mathrm{~g}}\left(3 \mathrm{~d}_{x y}, 3 \mathrm{~d}_{x^{2}-y^{2}}\right)$ doublet at lowest energy. However, multi-reference calculations based on the crystal structures of linear complexes, $\left[\mathrm{M}^{\mathrm{I}}\left(\mathrm{N}\left(\mathrm{SiMe}_{3}\right)_{2}\right)_{2}\right]^{-}$ (where $\mathrm{M}=\mathrm{Cr}, \mathrm{Mn}, \mathrm{Fe}, \mathrm{Co}$ ) all predict a d-orbital splitting with $3 \mathrm{~d}_{z^{2}}$ at lowest energy. ${ }^{5}$ Reasoning for this is due to strong $4 \mathrm{~s}-3 \mathrm{~d}_{z^{2}}$ mixing that weakens the anti-bonding character of the metal ion $3 \mathrm{~d}_{z^{2}}$ orbital. Experimental evidence and the associated implications of $4 \mathrm{~s}-3 \mathrm{~d}_{z^{2}}$ mixing on magnetic properties have been investigated on $\left[\mathrm{Fe}^{\mathrm{I}}\left(\mathrm{C}\left(\mathrm{SiMe}_{3}\right)_{3}\right)_{2}\right]^{-}{ }^{6}$ Calculations, based on the crystal structure, propose a $\mathrm{a}_{1 \mathrm{~g}}{ }^{2} \mathrm{e}_{2 \mathrm{~g}}{ }^{3} \mathrm{e}_{1 \mathrm{~g}}{ }^{2}$ ground state configuration with an almost unquenched $L=2$ orbital angular momentum. These calculations are supported and found consistent with Mössbauer spectroscopy data ${ }^{7}$ and highresolution single-crystal crystallography provides the first experimental evidence of $3 \mathrm{~d}_{z^{2}}{ }^{2}$ electron occupation from electron density analysis. ${ }^{8}$ However, despite the increasing number of reports of new linear transition metal SIMs ${ }^{9}$ there have been very few experimental studies beyond the characterisation of orientation averaged magnetism. In this paper we demonstrate $\mathrm{X}$-ray absorption spectroscopies as an accurate means to characterise the geometric and electronic structure of two coordinate transition metal SIMs.

We report results of extended X-ray absorption fine structure (EXAFS), X-ray absorption near edge spectroscopy (XANES), K $\beta$ Xray emission spectroscopy (XES) and $\mathrm{L}_{2,3}$-edge X-ray absorption spectroscopy (XAS) single-crystal measurements on $\mathrm{Li}_{2}\left(\mathrm{Li}_{1-x} \mathrm{Fe}_{x}\right)$ $\mathrm{N}$. Each of these techniques have specific sensitivities associated with transition selection rules and generated core-holes. A schematic overview of the spectroscopic techniques and associated transitions are shown in Fig. 1. K-edge XANES probes unoccupied $4 \mathrm{p}$ orbitals with $1 \mathrm{~s} \rightarrow 4 \mathrm{p}$ dipole transitions and unoccupied $3 \mathrm{~d}$ orbitals via the much weaker intensity pre-edge, $1 \mathrm{~s} \rightarrow 3 \mathrm{~d}$, transitions. The technique has particular sensitivity to local coordination symmetry, making it ideally suited for probing distortions from a linear, $D_{\infty \mathrm{h}}$, to a bent, $C_{2 \mathrm{v}}$, coordination. Bending leads to a pseudo Jahn-Teller effect that mixes $4 \mathrm{p}_{x, y}$ character into $3 \mathrm{~d}_{x z, y z}$. This mixing can be clearly identified since it drives strong dipole intensity enhancement in the pre-edge. EXAFS quantifies interference effects due to electron scattering from the surrounding atoms. K $\beta$ XES involves the ionisation of a 1 s electron and the detection of photons emitted from occupied $3 p$ and occupied valence-electrons filling the $1 \mathrm{~s}$ core-hole. Inter-shell $3 \mathrm{~d}-3 \mathrm{p}$ Coulomb exchange makes K $\beta$ XES a sensitive probe of $3 \mathrm{~d}$ spinstate in $\mathrm{Li}_{2}\left(\mathrm{Li}_{1-x} \mathrm{Fe}_{x}\right) \mathrm{N}$ as a function of concentration, $x \cdot{ }^{10} \mathrm{~L}_{2,3^{-}}$ edge XAS probes $2 \mathrm{p} \rightarrow 3 \mathrm{~d}$ dipole transitions providing direct

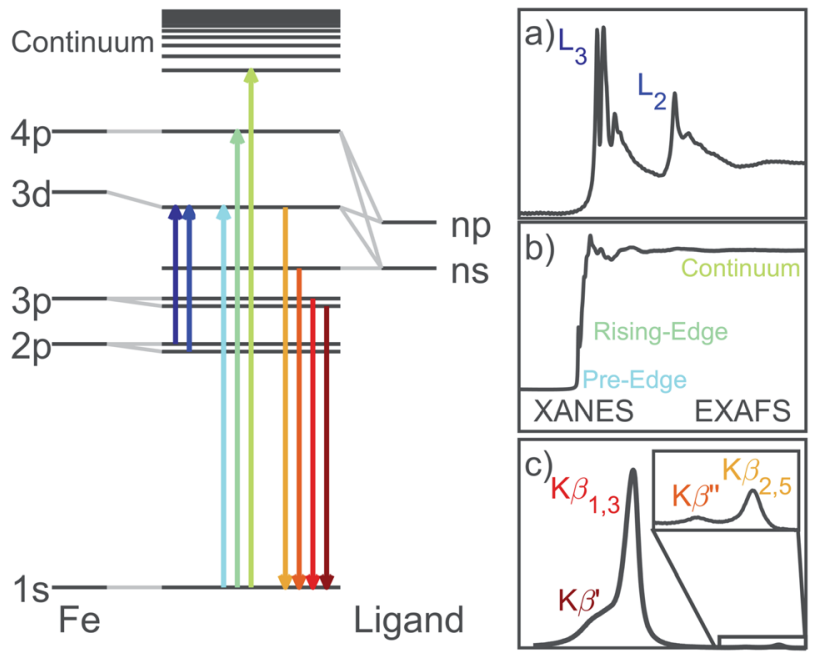

Fig. 1 Illustration of the Fe X-ray spectroscopic techniques with the associated transitions. (a) $\mathrm{L}_{2,3}$-edge absorption probes unoccupied $3 \mathrm{~d}$ orbitals. Spin-orbit coupling within the $2 \mathrm{p}^{5}$ core-hole splits the absorption into the $2 p_{1 / 2}$ and $2 p_{3 / 2}$ edges. (b) $\mathrm{K}$-edge pre-edge, edge and EXAFS correspond to $1 \mathrm{~s}$ absorptions into unoccupied $3 \mathrm{~d}, 4 \mathrm{p}$ and continuum respectively. (c) Following the ejection of a 1 s electron, $K \beta$ XES involves the decay of Fe $3 p$ and occupied valence electrons into the $1 \mathrm{~s}$ core-hole.

experimental access to the ligand field, related $4 \mathrm{~s}-3 \mathrm{~d}_{z^{2}}$ mixing, spin-orbit coupling and the resultant anisotropy barrier. ${ }^{11}$

Magnetisation studies for low Fe doping concentrations show hysteresis is maintained up to $16 \mathrm{~K}$ with sweep rates of 15 $\mathrm{mT} \mathrm{s}^{-1},{ }^{12}$ which is the largest temperature reported for a transition metal SIM. The effective energy barrier to magnetisation reversal is estimated between 37.1 and $40.2 \mathrm{meV}$ (298.9 and $\left.324.6 \mathrm{~cm}^{-1}\right) .{ }^{12}$ Below a blocking temperature of $\sim 10 \mathrm{~K}$ relaxation to magnetisation becomes temperature independent, with an exceptionally long magnetic relaxation time of $\tau>10^{4} \mathrm{s.}^{13}$ However, despite several theoretical ${ }^{\mathbf{1 , 1 4 , 1 5}}$ and experimental ${ }^{13,16-19,55}$ studies, the electronic structure of $\mathrm{Li}_{2}\left(\mathrm{Li}_{1-x} \mathrm{Fe}_{x}\right) \mathrm{N}$ remains a matter of considerable contention. Even the oxidation state of Fe sites has been brought into question by recent $a b$ initio calculations proposing the presence of $\mathrm{Li}$-ion vacancies coupled to $\mathrm{Fe}^{\mathrm{II}}$ sites. ${ }^{20}$ Fig. 2 shows the proposed structure of a single $\mathrm{Fe}$ dopant site present within $\mathrm{Li}_{2}\left(\mathrm{Li}_{1-x} \mathrm{Fe}_{x}\right) \mathrm{N}$ and possible ground state electronic configurations for both the

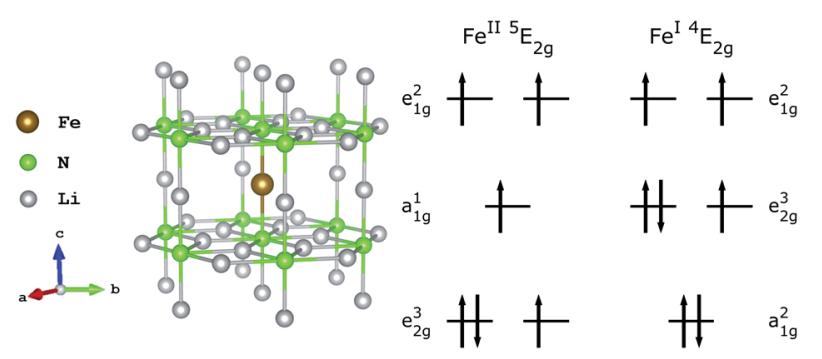

Fig. 2 (left) Structure of $\mathrm{Li}_{2}\left(\mathrm{Li}_{1-x} \mathrm{Fe}_{x}\right) \mathrm{N}$; Fe substitution within $\alpha-\mathrm{Li}_{3} \mathrm{~N}$ matrix at the $1 b$ Wyckoff position. (right) Proposed Fe"l and Fe' electron occupations. ${ }^{20}$ 
divalent and mono-valent situations. Additional open questions arise due to the inaccessibility of low concentration Fe sites embedded within the host structure, and presence or absences of Fe dopant clustering effects and concentration dependencies. In this paper we apply the range of X-ray spectroscopies that selectively characterise different aspects of electronic structure, from which we identify $\mathrm{Li}_{2}\left(\mathrm{Li}_{1-x} \mathrm{Fe}_{x}\right) \mathrm{N}$ is a high symmetry solid state SIM clear of stoichiometric vacancies where $\mathrm{Fe}$ lattice sites are geometrically equivalent. The geometric and electronic structure of $\mathrm{Li}_{2}\left(\mathrm{Li}_{1-x} \mathrm{Fe}_{x}\right) \mathrm{N}$ is compared against molecular based SIMs and important insights into the origin of high temperature magnetic blocking and exceptionally long magnetic relaxation times observed in $\mathrm{Li}_{2}\left(\mathrm{Li}_{1-x} \mathrm{Fe}_{x}\right) \mathrm{N}$ are obtained.

\section{Experimental section}

\subsection{Preparation of $\mathrm{Li}_{2}\left(\mathrm{Li}_{1-x} \mathrm{Fe}_{x}\right) \mathrm{N}$}

Single crystal growth of $\mathrm{Li}_{2}\left(\mathrm{Li}_{1-x} \mathrm{Fe}_{x}\right) \mathrm{N}$ was achieved through a Li-rich solution to a desired concentration, $x$, and verified by inductively coupled plasma mass spectrometry (detailed information on crystal synthesis reported by Jesche and Canfield in ref. 2). $\mathrm{Li}_{2}\left(\mathrm{Li}_{1-x} \mathrm{Fe}_{x}\right) \mathrm{N}$ crystallises as a hexagonal lattice of $\mathrm{Li}_{2} \mathrm{~N}$ layers alternating with $\mathrm{Li}_{1-x} \mathrm{Fe}_{x}$ planes perpendicular to the crystallographic $c$ axis. Dopant Fe site substitution replaces a Li$1 b$ Wyckoff position ion, Fig. 2. Crystal growth stipulates the crystallographic $c$ axis (magnetic easy-axis) to be oriented surface normal enabling accurate mounting of single crystals to easily perform angular dependence measurements.

\subsection{K-edge XANES, EXAFS and K $\beta$ XES measurements}

XANES, EXAFS and K $\beta$ XES measurements were performed using the high-resolution fluorescence-detection available at the I20-scanning beam-line at Diamond Light Source, UK, and exploiting a four-bounce $\mathrm{Si}(111)$ monochromator for spectral purity. ${ }^{21}$ The XES measurements were collected by a medipix detector from three $\mathrm{Si}(531)$ analyser crystals. XANES and EXAFS measurements were detected with a 64 element Ge detector windowed to the $\mathrm{K} \alpha$ fluorescence line. XANES monochromatic energy ranges; 7000-7075 eV, $5 \mathrm{eV}$ step size, $1 \mathrm{~s}$ integration (preedge), 7075-7100 eV, decreasing step size 5-0.5 eV, 1 s integration (rising-edge), 7100-7135.5 eV, $0.5 \mathrm{eV}$ step size, $1 \mathrm{~s}$ integration (XANES), 7135.5-8100 eV, $0.04 \AA$, increasing integration time from $1-5 \mathrm{~s}$ (EXAFS). $\mathrm{K} \beta$ emission energy ranges; 7025-7080 eV, $0.3 \mathrm{eV}$ step size, $1 \mathrm{~s}$ int. time ( $\mathrm{K} \beta$ mainline), 7080$7120 \mathrm{eV}, 0.2$ step size, $5 \mathrm{~s}$ integration time (valence-to-core). Several spectra were acquired for each doping concentration. $\mathrm{K} \beta$ measurements were performed with the incident energy set above the Fe K-edge at $8500 \mathrm{eV}$. The XANES, EXAFS and $\mathrm{K} \beta$ measurements were performed at room temperature. Additional $\mathrm{K} \beta$ measurements at $80 \mathrm{~K}$ exhibited negligible difference with respect to measurements at room temperatures. To minimise diffraction induced distortions within EXAFS spectra, crystals of $\mathrm{Li}_{2}\left(\mathrm{Li}_{1-x} \mathrm{Fe}_{x}\right) \mathrm{N}$ were ground into powdered pellets where possible. However, it is reported that the host crystal $\mathrm{Li}_{3} \mathrm{~N}$ exhibits an additional high pressure phase, of which grinding can induce a partial phase transformation of the $\mathrm{Li}_{3} \mathrm{~N}$ lattice from the $\alpha$ to $\beta$ phase. ${ }^{22}$ The XANES spectra of $\alpha$ and $\beta \operatorname{Li}_{2}(-$ $\left.\mathrm{Li}_{1-x} \mathrm{Fe}_{x}\right) \mathrm{N}$ differ significantly. Therefore XANES measurements were performed on both single-crystal and powder samples, from which it was deduced that only the lowest concentration $\mathrm{Li}_{2}\left(\mathrm{Li}_{1-x} \mathrm{Fe}_{x}\right) \mathrm{N}$ sample was affected by grinding. For this reason the measurements performed on $\mathrm{Li}_{2}\left(\mathrm{Li}_{1-x} \mathrm{Fe}_{x}\right) \mathrm{N}$ for $x=$ $0.0020(5)$ were on a single crystal while for $x=0.0063(4)$ and $0.0093(6)$ were undertaken on powder samples. Powder samples were formed into pellets and mixed with boron nitride to an appropriate dilution to minimise self-absorption effects. Samples of $\mathrm{Li}_{2}\left(\mathrm{Li}_{1-x} \mathrm{Fe}_{x}\right) \mathrm{N}$ were prepared within an argon atmosphere glove-box $\left(<0.5\right.$ ppm $\mathrm{O}_{2}$ and $\left.\mathrm{H}_{2} \mathrm{O}\right)$ where single crystals and powders were encapsulated with Kapton tape. Measurements were performed within a nitrogen gas atmosphere. XANES and EXAFS analysis was undertaken within the Athena and Artemis packages. ${ }^{23}$ Background subtraction was undertaken with a linear fitting of the pre-edge and normalisation through a third order polynomial of the post-edge. Bond length $(R)$ and Debye-Waller factor $(\sigma)$ were used as variables of fitting for neighbouring lithium and nitrogen atoms. A Levenberg-Marquardt non-linear least-squares minimisation was applied for EXAFS fitting. K $\beta$ XES spectra are normalised through a trapezoidal integration and the subtraction of a constant. Angular dependent XANES measurements were performed at the BL9-3 beamline at SSRL. The measurements were performed at $10 \mathrm{~K}$ in transmission mode on a $1 \mathrm{~mm}$ thick single crystal. These measurements were performed with monochromatic energy ranges; 6785-7085 $6 \mathrm{eV}$ step size, $1 \mathrm{~s}$ integration (pre-edge), 7085-7150 eV, $0.15 \mathrm{eV}$ step size, $1 \mathrm{~s}$ integration (rising-edge), 7150-8359.5 eV, $0.5 \mathrm{eV}$ step size, $1 \mathrm{~s}$ (post-edge region). Background subtraction of main K-edge XANES isolates the rising-edge peak from which Pearson VII peak fitting was undertaken through a least-squares minimisation, Fig. S3.†

\section{$2.3 \quad \mathrm{~L}_{2,3}$-edge XAS measurements}

$\mathrm{L}_{2,3}$-edge XAS measurements were performed at the I10 high field magnet end station at Diamond Light Source. Fast energy XAS scans were performed between $690-755 \mathrm{eV}$ with $0.1 \mathrm{eV}$ step sizes. The measurements were performed between 4.5-400 K within an ultra-high vacuum $\left(10^{-10}\right.$ bar $)$. Detection was performed via total fluorescence yield in a back-scattering geometry using a $10 \times 10 \mathrm{~mm}^{2}$ silicon diode with a $150 \mathrm{~nm} \mathrm{Al}$ cover to filter out electrons. Single crystals of $\mathrm{Li}_{2}\left(\mathrm{Li}_{1-x} \mathrm{Fe}_{x}\right) \mathrm{N}$ are too insulating to obtain drain current detected XAS. Single crystals were mounted within an argon glovebox with Torr Seal epoxy resin and transferred to experimental chamber through a nitrogen purged glovebag. Background subtraction of the spectra was performed with a linear fitting of the pre-edge (690$700 \mathrm{eV}$ ) and normalisation through a linear fitting of the post edge (735-750 eV). The $2 \mathrm{p}_{3 / 2}$ and $2 \mathrm{p}_{1 / 2}$ continuum transitions were subtracted through a double arctangent function ${ }^{24}$ (further details see ESI Fig. S4†).

Ligand field multiplet simulations of the $\mathrm{L}_{2,3}$-edge XAS results were performed using the quantum many-body scripting 
language, Quanty. ${ }^{25}$ The Quanty input files for the simulation of $\mathrm{L}_{2,3}$-edge fluorescence XAS were adapted from templates generated in Crispy. ${ }^{26}$ Multiplet effects are described by the Slater-Condon-Shortley parameters, $F_{\mathrm{pp}}^{\mathrm{k}}, F_{\mathrm{pd}}^{\mathrm{k}}$ (Coulomb) and $G_{\mathrm{pd}}^{\mathrm{k}}$ (exchange), reduced to $80 \%$ of the Hartree-Fock calculated values to account for the over-estimation of electron-electron repulsion found for the free ion. The $2 \mathrm{p}^{5}$ spin-orbit coupling parameter $\xi_{2 p}$ is found consistent with the atomic value (8.202 $\mathrm{eV}$ ). The $3 \mathrm{~d}$ spin-orbit coupling parameters were obtained by fitting to the temperature dependence of the $\mathrm{L}_{2,3}$-edge XAS, giving $\xi_{3 \mathrm{~d}}=0.052$ and $0.068 \mathrm{eV}$ for the initial and final states respectively. The presence of $4 \mathrm{~s}$ mixing in linear transition metal complexes is known to weaken the $3 \mathrm{~d} \sigma$ anti-bonding character and reducing the energy of the $3 \mathrm{~d}_{z^{2}}$ orbital. This effect is accounted for in a simple $3 \mathrm{~d}$ ligand field model, where the relative energy of the orbitals are adjusted with parameters $D_{\mathrm{q}}, D_{\mathrm{t}}$ and $D_{\mathrm{s}}$, in the $D_{6 \mathrm{~h}}$ point group. The ligand field parameters describe the d-orbital degeneracy and energy splittings of the $\mathrm{A}_{1 \mathrm{~g}}\left(3 \mathrm{~d}_{z^{2}}\right)$ singlet, and two E doublets, $\mathrm{E}_{1 \mathrm{~g}}\left(\mathrm{~d}_{x y}, \mathrm{~d}_{y z}\right)$ and $\mathrm{E}_{2 \mathrm{~g}}(-$ $\left.\mathrm{d}_{x^{2}-y^{2}}, \mathrm{~d}_{x y}\right)$. A local linear coordination geometry is characterised by a $D_{\infty \mathrm{h}}$ ligand-field, and has equivalence with $D_{6 \mathrm{~h}}$ when $D_{\mathrm{q}}=$ 0 . Broadening of the transitions as described by the core-hole lifetime was applied through a Lorentzian function over the $\mathrm{L}_{3}$ and $\mathrm{L}_{2}$ edge of $0.35 \mathrm{eV}$ and $0.7 \mathrm{eV}$ full width half maximum (FWHM) respectively. Gaussian broadening due to the instrumental resolution was set to $0.25 \mathrm{eV}$ FWHM and simulated at $4.5 \mathrm{~K}$.

\subsection{Calculation details}

The density functional theory (DFT) calculations presented in this work were performed using the plane-wave pseudopotential DFT method available within the codes Quantum-Espresso ${ }^{27}$ and CASTEP. ${ }^{28}$ Generalised-gradient approximation for the exchange-correlation energy was selected in the form of PBE functional. ${ }^{29}$ Ultrasoft pseudopotentials were used for PBE and $\mathrm{PBE}+\mathrm{U}$ calculations, whereas relativistic ultrasoft pseudopotentials were used for the non-collinear calculations including spin-orbit coupling. The pseudopotentials for use with Quantum-Espresso were taken from the PSlibrary ${ }^{30}$ while the pseudopotentials for use with CASTEP were generated self consistently. A kinetic energy cutoff of 90 Ry for the wave function and of 900 Ry for the charge density together with a (6 $\times 6 \times 6)$ Monkhorst-Pack $k$-point grid were determined as parameters for convergence calculations. A $(10 \times 10 \times 10) k$ point grid was instead used for the calculation of the density of states (DOS). Self-consistent calculations were performed to a convergence value of $1 \times 10^{-7} \mathrm{eV}$. Due to the isolated nature of Fe atoms in $\mathrm{Li}_{2}\left(\mathrm{Li}_{1-x} \mathrm{Fe}_{x}\right) \mathrm{N}$, we operated with a $3 \times 3 \times 3$ supercell constructed from the hexagonal cell of $\mathrm{Li}_{3} \mathrm{~N}$ having space group $P 6 / \mathrm{mmm}$. The structure was relaxed so that the $\mathrm{Fe}-$ $\mathrm{N}$ and $\mathrm{Fe}-\mathrm{Li}$ distances in the first coordination shells of iron matched the distances evaluated from the analysis of EXAFS results. The reliability of the experimentally evaluated structure for simulations was tested by completing a relaxation up to an energy change of $3 \times 10^{-6} \mathrm{eV}$ per atom, which produced a structure yielding a shorter Fe-N distance but a comparable density of states. A smearing of 0.01 Ry was applied to the computed eigenvalues in order to improve the $k$-point convergence. The angular dependence of Fe K-edge was calculated including the effects of core-hole ${ }^{31}$ and using the same $k$-point grid as previously used for the DOS. Ground state DFT was then expanded by expressing the exchange-correlation potential in terms of local-density band theory via the PBE+U method..$^{32}$ The electronic properties were calculated with the simplified, rotational-invariant formulation developed within the linear response approach. ${ }^{33}$ An effective $U$ value of $4 \mathrm{eV}$ was included in such calculations, as previously estimated for similar compounds. ${ }^{34}$ Angular-momentum dependent orbital occupation was determined with Löwdin charge analysis on top of ground-state, converged DFT wavefunctions. X-ray absorption spectra were computed by extracting the matrix elements for electronic interband transitions from the ground state DFT including the local effects of 1 s core-hole as implemented in the code CASTEP. Such calculations were accomplished in the aforementioned supercell, in order to avoid interactions between periodic images of the core excitation. An energy shift of $7110.5 \mathrm{eV}$ was applied to match the experimental data and normalised through trapezoidal integration of simulated spectrum. Transition broadening as a consequence of instrumental resolution (Gaussian) and core-lifetime effects (Lorentzian) was set as 0.2 and $1.25 \mathrm{eV}$ FWHM respectively.

\section{Results and discussion}

\subsection{Extended X-ray absorption fine structure (EXAFS)}

To precisely quantify the local coordination environment at Fe sites EXAFS measurements were performed on samples with low dopant concentrations, where $x=0.0020(5), 0.0053(4)$ and $0.0093(6)$. The $k^{3}$ weighted spectra are presented in Fig. 3a which highlight the EXAFS Fourier transform region as $3 \leq k \leq$ $10 \AA^{-1}$ for $x=0.0020(5)$ and $3 \leq k \leq 12 \AA^{-1}$ for $x=0.0053(4)$ and $0.0093(6)\left(E_{0}=7113 \mathrm{eV}\right)$. Single crystal measurements were performed with $E 45^{\circ}$ relative to the crystallographic $c$ axis on the lowest concentration $(x=0.0020(5))$ sample resulting in significant Bragg peaks for $k$ values greater than $10 \AA^{-1}$, requiring a reduced Fourier transform range.

EXAFS fitting was undertaken using a model including a single Fe atom dopant within $\alpha-\mathrm{Li}_{3} \mathrm{~N}$ as an initial structure $(a$ $=3.652(8) \AA$ and $c=3.870(10) \AA$, Fig. 2). The selected scattering paths were limited up to a radial distance of $3.5 \AA$; these included two single scattering pathways (Fe-N-Fe, $\mathrm{Fe}-\mathrm{Li}-\mathrm{Fe}$ ) and one double scattering path (Fe-N-Li-Fe). Fitting of the experimental data was undertaken for each concentration individually. The EXAFS fit parameter results are presented in Table 1 . The coordinated nitrogen atoms characterise the first spectral peak centred at $1.5 \AA$, Fig. 3b, while scattering from the hexagonally bonded lithium atoms in combination with the double scattering path characterise the remaining spectral features. The Fe-N bond lengths were determined to be 1.873(7) $\AA$, 0.062(7) A shorter than the equivalent $\mathrm{Li}-\mathrm{N}$ bond length. This finding is consistent with X-ray diffraction results that show $c$ axis contraction and $a$ and $b$-axis expansion on increasing $\mathrm{Fe}$ concentration. ${ }^{12,16,35}$ The length of the Fe-N bond is very short in 

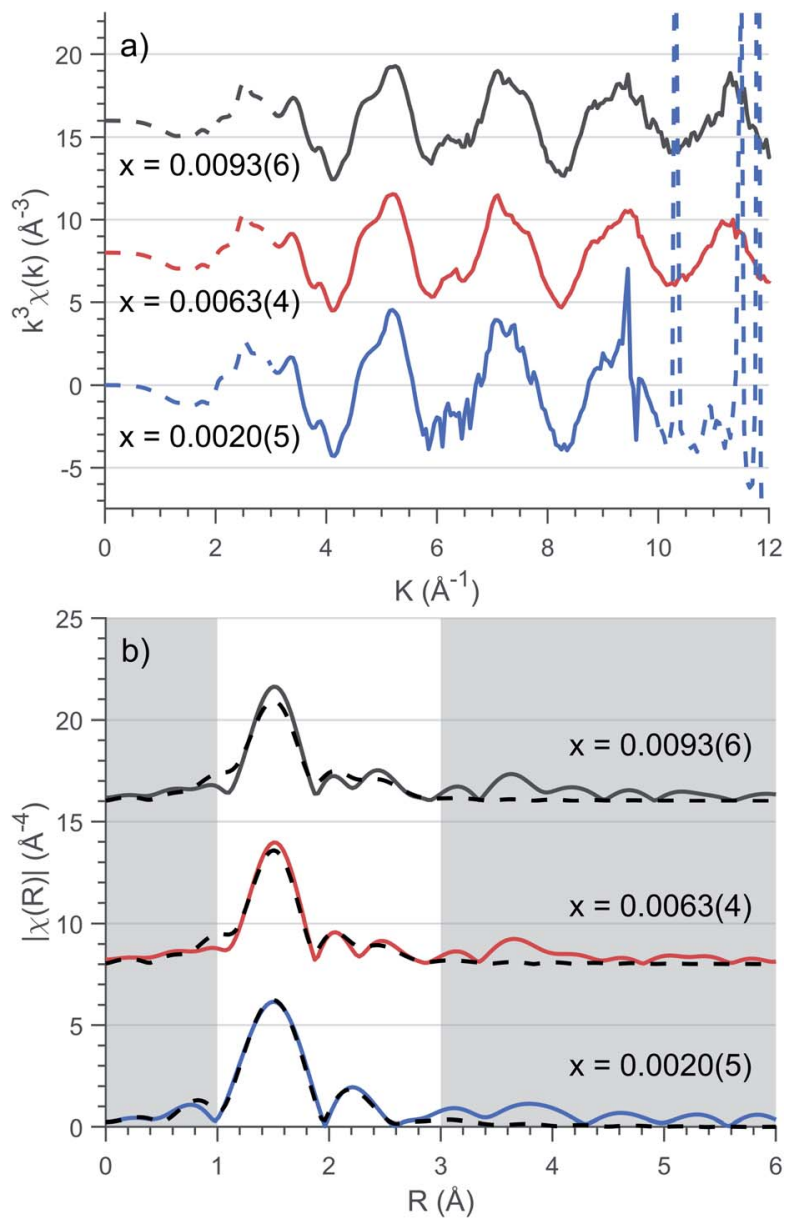

Fig. 3 (a) Background subtracted $k^{3}$ weighted XAFS spectra of various concentrations, $x$. Solid lines represent the Fourier transform region for EXAFS fitting. (b) Fitting of Fourier transformed $k^{3}$-weighted EXAFS spectra for $\mathrm{Li}_{2}\left(\mathrm{Li}_{1-x} \mathrm{Fe}_{x}\right) \mathrm{N}$ as a function of concentration, $x$. EXAFS fitting is represented as dashed lines with corresponding parameters presented in Table 1.

comparison with values reported for two coordinate $\mathrm{Fe}^{\mathrm{I}}-\mathrm{N}$, including the linear complex $\left[\mathrm{K}\left(18\right.\right.$-crown-6][ $\left.\mathrm{Fe}\left(\mathrm{N}\left(\mathrm{SiMe}_{3}\right)_{2}\right)_{2}\right]$ $(1.9213(6) \AA)^{36}$ and the slightly bent $\left[\mathrm{Fe}\left(\mathrm{N}\left(\mathrm{SiMe}_{3}\right) \mathrm{Dipp}\right)_{2}\right]^{-}(1.91$ Å). ${ }^{37}$ The Fe-N length found for $\mathrm{Li}_{2}\left(\mathrm{Li}_{1-x} \mathrm{Fe}_{x}\right) \mathrm{N}$ compares more favourably with the linear divalent complex $\left[\mathrm{Fe}\left(\mathrm{N}\left(\mathrm{SiMe}_{3}\right) \mathrm{Dipp}\right)_{2}\right]$ with a reported $\mathrm{Fe}^{\mathrm{II}}-\mathrm{N}$ length of $1.853(1) \AA{ }^{38}$ Many-body

Table 1 EXAFS fitting parameters of various Fe doping concentrations, $x$ of $\mathrm{Li}_{2}\left(\mathrm{Li}_{1-x} \mathrm{Fe}_{x}\right) \mathrm{N}$; $R$-factor $(R)$, Energy alignment $(\Delta E), \mathrm{Fe}-\mathrm{N}$ and $\mathrm{Fe}-\mathrm{Li}$ Bond Lengths $\left(R_{\mathrm{N}}\right.$ and $R_{\mathrm{Li}}$ respectively) and Debye-Waller factor $\left(\sigma^{2}\right)$ for lithium (Li) and nitrogen (N) scattering atoms. Amplitude reduction factor, $S_{0}^{2}$ fixed to 0.92

\begin{tabular}{llll}
\hline$x$ & $0.0020(5)$ & $0.0063(4)$ & $0.0093(6)$ \\
\hline$R$ & 0.004 & 0.028 & 0.061 \\
$\Delta E(\mathrm{eV})$ & $10.85 \pm 0.93$ & $9.35 \pm 1.84$ & $9.73 \pm 2.85$ \\
$R_{\mathrm{N}}(\AA)$ & $1.873 \pm 0.007$ & $1.869 \pm 0.015$ & $1.868 \pm 0.023$ \\
$\sigma_{\mathrm{N}}{ }^{2}\left(\AA^{2}\right) \times 10^{-3}$ & $0.7 \pm 0.5$ & $3.4 \pm 1.0$ & $4.9 \pm 1.6$ \\
$R_{\mathrm{Li}}(\AA)$ & $2.867 \pm 0.015$ & $2.840 \pm 0.025$ & $2.845 \pm 0.039$ \\
$\sigma_{\mathrm{Li}}{ }^{2}\left(\AA^{2}\right) \times 10^{-3}$ & $20.4 \pm 3.0$ & $19.6 \pm 4.5$ & $17.9 \pm 5.8$
\end{tabular}

quantum chemistry calculations performed on Fe doped lithium nitride units $\left[\mathrm{Fe}^{\mathrm{I}} \mathrm{N}_{2} \mathrm{Li}_{14}\right]^{9+}$ and $\left[\mathrm{Fe}^{\mathrm{II}} \mathrm{N}_{2} \mathrm{Li}_{13}\right]^{9+}$ report bond lengths of $1.92 \AA$ and $1.88 \AA$ respectively. ${ }^{20}$ In summary, comparison with reported $\mathrm{Fe}-\mathrm{N}$ bond lengths for two coordinate complexes might suggest a divalent oxidation state for $\mathrm{Li}_{2}\left(\mathrm{Li}_{1-x} \mathrm{Fe}_{x}\right) \mathrm{N}$. Indeed this was the conclusion reported by Muller-Bouvet et al. (ref. 39) for Co doped lithium nitride, where EXAFS analysis included the pairing of dopants with Li vacancies at $2 c$ sites, from which a formula of $\mathrm{Li}_{3-2 x} \mathrm{Co}_{x} \mathrm{~N}$ with a divalent Co oxidation state is proposed. ${ }^{39}$

The EXAFS measurements are consistent with isolated $\mathrm{Fe}$ dopants with no indication of clustering evidenced through the lack of strong features beyond the first structural peak at $1.5 \AA$. While not conclusive there is an observed increase in $R$-factor with concentration which could be attributed to the requirement of incorporating small contributions from $\mathrm{Fe}-\mathrm{Fe}$ and $\mathrm{Fe}-$ $\mathrm{N}-\mathrm{Fe}$ scattering paths within the $a b$ plane and along the $c$ axis respectively.

According to combinatorial analysis, the probability of locating $n \mathrm{Li}$ ions at the 8 possible neighbouring sites (6 perpendicular and 2 parallel to the crystallographic $c$ axis) for a dopant Fe ion is expressed as: $W_{n}=8 ![n !(8-n) !]^{-1}(1-$ $x)^{n} x^{8-n} \cdot{ }^{40}$ At the highest doped concentration, $x=0.0093(6)$, the probability of all 8 neighbouring atoms being lithium is $92.8 \%$, at which point there begins to be a non-negligible requirement of additional scattering pathways to account for Fe dimerisation. However, the number of available independent parameters, dictated by the Nyquist theorem $\left(N_{\text {idp }}=\frac{2 \Delta k \Delta R}{\pi}+1\right)^{41}$ prohibits the inclusion of multiple Fe ions within the model.

\subsection{X-ray absorption near-edge structure (XANES)}

Transition metal oxidation state is frequently characterised by the K-edge threshold energy and the characteristic multiplet effects present within the $\mathrm{K}$ pre-edge..$^{42} \mathrm{Fe}$ K-edge XANES measurements on a polycrystalline sample of $\mathrm{Li}_{2}\left(\mathrm{Li}_{1-x} \mathrm{Fe}_{x}\right) \mathrm{N}$ was previously investigated by Niewa et al..$^{17,43}$ The threshold energy region of the XANES was found to be dominated by an intense transition centred at $7113 \mathrm{eV}$. The origin of the $7113 \mathrm{eV}$ peak was assigned by Niewa et al..$^{17,43}$ as a K pre-edge $(1 \mathrm{~s} \rightarrow 3 \mathrm{~d})$ transition, with enhanced intensity due to $4 \mathrm{p}$-mixing, from which a local $C_{2 \mathrm{v}}$ coordination symmetry was proposed. Since bending away from $180^{\circ}$ introduces mixing of $4 \mathrm{p}_{x}$ character into $3 \mathrm{~d}_{x z}$ and $4 \mathrm{p}_{y}$ into $3 \mathrm{~d}_{y z}$ due to transformations under the same irreducible representations in $C_{2 v}$. To further investigate Fe site coordination symmetry, we preformed angular dependent single-crystal $\mathrm{Fe}$ K-edge XANES measurements of $\mathrm{Li}_{2}\left(\mathrm{Li}_{0.985^{-}}\right.$ $\left.\mathrm{Fe}_{0.015}\right)$ N, Fig. 4 and S2. $\dagger$ The area of the $7113 \mathrm{eV}$ peak for each sample orientation gives the angular dependence of the transition oscillator strength, Fig. 4. Measurements were experimentally limited from $0-45^{\circ}$, where $0^{\circ}$ corresponds with $E \perp c$ and $90^{\circ}$ with $E \| c$. Maximum intensity of the transition is observed at $0^{\circ}$. The variation in intensity as a function of crystal orientation follows a sinusoidal profile with a minimum at $90^{\circ}$; this is indicative of the two fold symmetry of dipole transitions with $4 \mathrm{p}_{x, y}$ orbital character. The XANES of linear $\mathrm{Cu}^{\mathrm{I}}$ complexes 


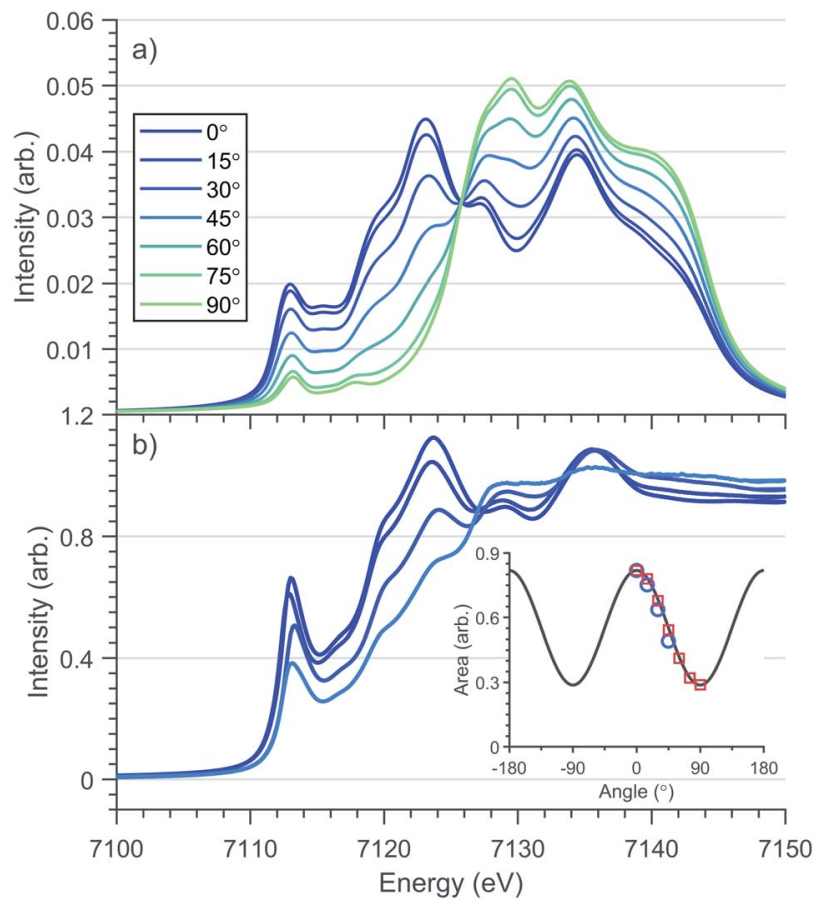

Fig. 4 Single crystal angular dependent Fe $\mathrm{K}$-edge XANES of $\mathrm{Li}_{2}(-$ $\mathrm{Li}_{1-x}\left(\mathrm{Fe}_{\chi}\right) \mathrm{N}(\mathrm{a}) \mathrm{DFT}$ calculations (b) experimental spectra with a nominal concentration of $x=0.015$. $0^{\circ}$ corresponds with $E \perp c$ and $90^{\circ}$ with $E \| c$. (Inlay) Angular dependence of $1 s-4 p_{x, y}$ transition intensity of experimental $(C)$ and theoretical $(\square)$ rising-edge peak centred at $7113 \mathrm{eV}$.

are known to exhibit very low energy rising edge features due to transitions directly into degenerate $4 \mathrm{p}_{x, y}$ states, ${ }^{\mathbf{4 4}}$ however the XANES of open-shell linear transition metal complexes are less developed. The $7113 \mathrm{eV}$ feature in $\mathrm{Li}_{2}\left(\mathrm{Li}_{0.985} \mathrm{Fe}_{0.015}\right) \mathrm{N}$ is consistent with the crystal field model originally proposed for $\mathrm{Cu}^{\mathrm{I}}$, whereby the linear coordination lifts the $4 \mathrm{p}_{x, y, z}$ degeneracy, decreasing the energy of the degenerate $4 \mathrm{p}_{x, y}$ orbitals that are non-bonding and increasing the $4 \mathrm{p}_{z}$ orbital to a higher energy. To obtain conclusion of the origin of the $7113 \mathrm{eV}$ peak, and the associated local symmetry of the Fe site, DFT calculations based on a linear geometry were found to accurately reproduce the angular dependent XANES of $\mathrm{Li}_{2}\left(\mathrm{Li}_{0.985} \mathrm{Fe}_{0.015}\right) \mathrm{N}$, Fig. 4 . Projection of the density of states from this resultant DFT simulation verifies the interpreted splitting and degeneracy of the Fe-4p orbitals. Unoccupied character above the Fermi energy (Fig. S5 $\dagger$ ) coincides with the expected degeneracy of the $4 \mathrm{p}_{x, y}$ orbitals at the energy of the rising edge feature with $4 \mathrm{p}_{z}$ orbital character shifted to higher energy. In summary, our angular dependent K-edge XANES analysis on $\mathrm{Li}_{2}\left(\mathrm{Li}_{0.985} \mathrm{Fe}_{0.015}\right)$ $\mathrm{N}$ identifies the local coordination symmetry involves a linear $\mathrm{N}-\mathrm{Fe}-\mathrm{N}$ motif; a conclusion that is further supported by our $\mathrm{L}_{2,3}$-edge analysis in the following section. The weak quadrupole allowed $1 \mathrm{~s} \rightarrow 3 \mathrm{~d} \mathrm{~K}$ pre-edge transitions are however unresolved due to overlap with the considerably more intense $7113 \mathrm{eV}$ feature. The absence of a resolvable pre-edge inhibits a ligand field multiplet analysis to quantitatively assign Fe spin ground-state by K-edge XANES.

\subsection{K $\beta$ X-ray emission spectroscopy}

Magnetisation measurements for $\mathrm{Li}_{2}\left(\mathrm{Li}_{1-x} \mathrm{Fe}_{x}\right) \mathrm{N}$ shows considerable dependence on $x .^{1}$ In a recent theoretical study, many-body quantum chemistry calculations on $\left[\mathrm{Fe}^{\mathrm{I}} \mathrm{N}_{2} \mathrm{Li}_{14}\right]^{9+}$ and $\left[\mathrm{Fe}^{\mathrm{II}} \mathrm{N}_{2}\right.$ $\left.\mathrm{Li}_{13}\right]^{9+}$ fragments show a strong reduction in magnetic anisotropy in going from a $\mathrm{Fe}^{\mathrm{I}}$ to $\mathrm{Fe}^{\mathrm{II}}$ dopant site. ${ }^{20}$ Previous studies have proposed that dopant sites couple to a finite number of $\mathrm{Li}$ ion vacancies giving rise to minority divalent species and a monovalent majority species with a ratio that changes as a function of dopant concentration..$^{20,39}$ To address this question and investigate the spin-ground state of $\mathrm{Li}_{2}\left(\mathrm{Li}_{1-x} \mathrm{Fe}_{x}\right) \mathrm{N}, \mathrm{K} \beta$ XES measurements were performed as a function of doping concentration, $x$, Fig. 5. Since K $\beta$ utilises a non-resonant incident photon energy it is less affected by self-absorption than resonant techniques, making it ideally suited to studying the Fe concentration dependence of electronic structure. The $K \beta$ mainline, $K \beta_{1,3}$ and $K \beta^{\prime}$, involves a dipole-allowed $3 \mathrm{p}-1$ s emission transition. These two mainline features have the advantage of being highly sensitive to spin ground-state, identified via differences in the $K \beta_{1,3}$ and $K \beta^{\prime}$ splitting and intensity. ${ }^{10}$ Fig. 5 shows $\mathrm{K} \beta$ measurements for $\mathrm{Li}_{2}(-$ $\left.\mathrm{Li}_{1-x} \mathrm{Fe}_{x}\right) \mathrm{N}$ where $x=0.1800(1), 0.0063(4)$ and $0.0020(5)$. There exists no electronic structural change as a function of doping concentration for $\mathrm{Li}_{2}\left(\mathrm{Li}_{1-x} \mathrm{Fe}_{x}\right) \mathrm{N}$; confirming no valence change with respect to concentration. Frequently $K \beta$ is applied to fingerprint the spin ground-state and to deduce the valence of transition metal ions. However, due to a lack of two coordinate $\mathrm{Fe}^{\mathrm{I}}$ reference spectra, such qualitative analysis is inhibited. Despite this, Fig. S1 $\uparrow$ compares the $\mathrm{Li}_{2}\left(\mathrm{Li}_{1-x} \mathrm{Fe}_{x}\right) \mathrm{N} \mathrm{K} \beta$-mainline spectrum with a series of six coordinate $O_{\mathrm{h}}$ and $D_{4 \mathrm{~h}} \mathrm{Fe}^{\mathrm{II}}$ and $\mathrm{Fe}^{\mathrm{III}}$ model complexes. ${ }^{45}$ The energy and intensity of the $\mathrm{K} \beta^{\prime \prime}$ first moment is consistent with either a $\mathrm{d}^{6}$ or $\mathrm{d}^{7}$ occupation of the Fe from which either $S=2$ or $3 / 2$ could be inferred. However, there is a significant deviation in the splitting and intensity between the $\mathrm{K} \beta_{1,3}$ and $K \beta^{\prime}$ of $\mathrm{Li}_{2}\left(\mathrm{Li}_{1-x} \mathrm{Fe}_{x}\right) \mathrm{N}$ with respect to the model complexes.

The valence to core $K \beta_{2,5}$ and $K \beta^{\prime \prime}$ peaks have significant sensitivity to the local bonding environment around Fe site. The

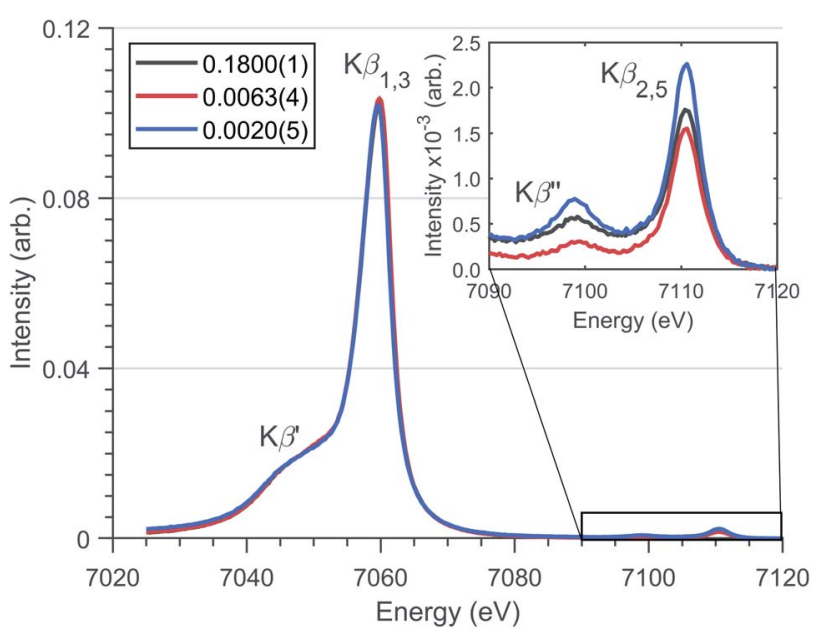

Fig. 5 Fe K $\beta$ XES spectrum of $\mathrm{Li}_{2}\left(\mathrm{Li}_{1-x} \mathrm{Fe}_{x}\right) \mathrm{N}$ for several concentrations ( $x$ values defined in legend) with spectral features highlighted. (Inlay) Magnified valence-to-core region. 
valence-to-core peaks at $7098.9 \mathrm{eV}$ and $7110.6 \mathrm{eV}$ (Fig. 5) correspond with metal character present within nitrogen $2 \mathrm{~s}$ and $2 p$ orbitals respectively. The lack of variation in the relative intensities and energies of these features is consistent with no variation in geometry around the $\mathrm{N}-\mathrm{Fe}-\mathrm{N}$ motif as a function of dopant concentration.

\section{$3.4 \quad \mathrm{~L}_{2,3}$-edge $\mathrm{X}$-ray absorption spectroscopy}

$\mathrm{L}_{2,3}$-edge XAS accesses the electronic structure at the $3 \mathrm{~d}$ orbitals through dipole allowed $2 \mathrm{p}-3 \mathrm{~d}$ transitions. Single crystal measurements were performed with $E \perp$ to the crystallographic $c$ axis and nominal doping concentration, $x=0.015$. Fig. $6 \mathrm{a}$ shows the $\mathrm{Fe}_{2,3}$-edge total-fluorescence spectrum measured at 4.5 K, with $\mathrm{L}_{3}$ and $\mathrm{L}_{2}$ edge peaks at $705.7 \mathrm{eV}$ and $720.3 \mathrm{eV}$ respectively. The $\mathrm{L}_{3}$-edge exhibits two intense features separated by $1.3 \mathrm{eV}$ whereas the $\mathrm{L}_{2}$-edge is dominated by a single intense peak. Both $\mathrm{L}_{2,3}$-edges exhibit a series of high energy satellite features indicating the presence of significant metalligand charge transfer.

$\mathrm{L}_{2,3}$-edge XAS ligand field multiplet fitting was performed to quantify the $3 \mathrm{~d}$ electronic structure of dopant sites. Two sets of simulations were performed based on both $\mathrm{Fe}^{\mathrm{I}}$ and $\mathrm{Fe}^{\mathrm{II}}$ scenarios. Initial fit parameters were extracted from the results of $a b$ initio results reported by $\mathrm{Xu}$ et $a l .{ }^{20}$ see Table $\mathrm{S} 1$ and Fig. S6. $\dagger$ Optimisation of the simulated spectral features relative to experiment were obtained through adjustment of the ligand field parameters $\left(D_{\mathrm{t}}\right.$ and $\left.D_{\mathrm{s}}\right)$ and include the effect of $4 \mathrm{~s}$ mixing through the reduction in energy of the $3 \mathrm{~d}_{z^{2}}$ orbital. Agreement with the measured spectrum could only be obtained for the $\mathrm{Fe}^{\mathrm{I}}$

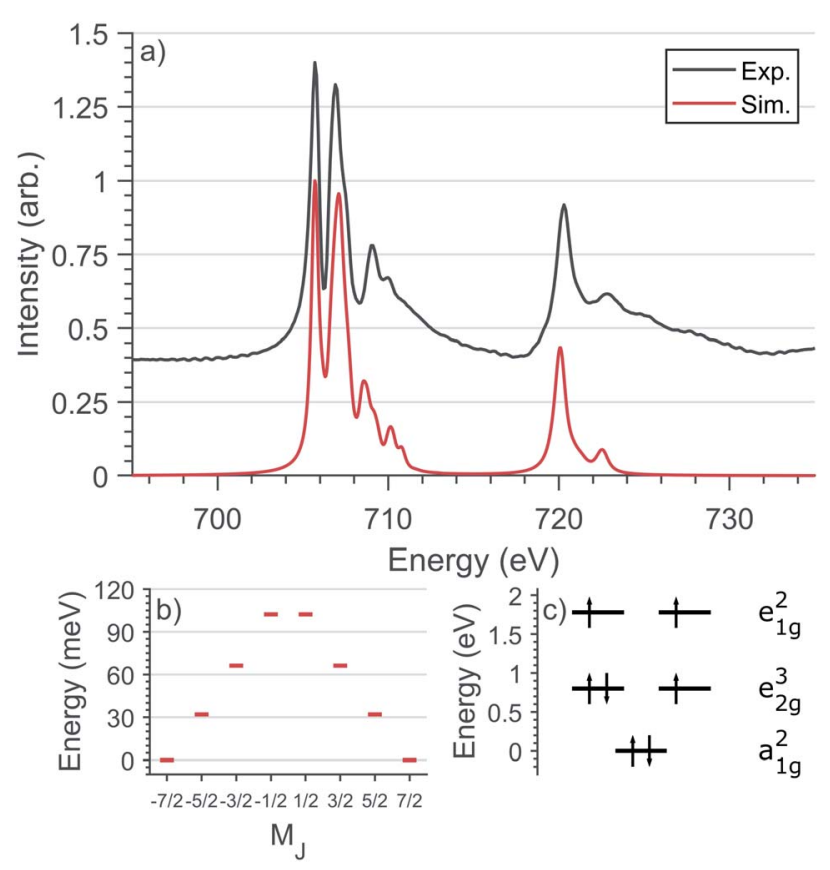

Fig. 6 (a) Comparison of experimental and simulated $F e L_{2,3}$-edge spectra at $4.5 \mathrm{~K}$ with $L_{3}$ peak normalisation. (b) The calculated $M_{J}$ splitting of the ground-state $J=7 / 2$ manifold. (c) The calculated energies of $3 d$ orbitals obtained from the $L_{2,3}$-edge ligand field multiplet fit. valence model, with best fit parameters of $D_{\mathrm{q}}=0, D_{\mathrm{t}}=0.1806$ and $D_{\mathrm{s}}=-0.0257 \mathrm{eV}$ corresponding to an electronic configuration such that $d_{z^{2}}$ has the lowest orbital energy, Fig. 6. The simulation quantifies the $\mathrm{Li}_{2}\left(\mathrm{Li}_{0.985} \mathrm{Fe}_{0.015}\right) \mathrm{N}$ dopant site as a $\mathrm{Fe}^{\mathrm{I}}$ $3 \mathrm{~d}^{7},{ }^{4} D_{7 / 2}$ ion, with a ${ }^{5} E$ symmetry ground state resulting from $\mathrm{a} \mathrm{e}_{1 \mathrm{~g}}{ }^{2} \mathrm{e}_{2 \mathrm{~g}}{ }^{3} \mathrm{a}_{1 \mathrm{~g}}{ }^{2}$ configuration. The experimentally determined ligand field splitting is larger than the reported CASSCF result for a $\left[\mathrm{Fe}^{\mathrm{I}} \mathrm{N}_{2} \mathrm{Li}_{14}\right]^{9+}$ fragment that gave energies of $0,0.91,1.5 \mathrm{eV}$ for $\mathrm{a}_{1 \mathrm{~g}}{ }^{2}, \mathrm{e}_{2 \mathrm{~g}}{ }^{3}$ and $\mathrm{e}_{1 \mathrm{~g}}{ }^{2}$ respectively. ${ }^{20}$ The energy reduction in $\mathrm{d}_{z^{2}}$ is approximately twice the value calculated for the linear monovalent SIM, $\left[\mathrm{Fe}\left(\mathrm{C}\left(\mathrm{SiMe}_{3}\right)_{3}\right)_{2}\right]^{-} .{ }^{6}$ Spin-orbit coupling splits the total angular momentum of Fe sites into four Kramers doublets. In order of increasing energy these doublets, $M_{\mathrm{J}}= \pm 7 /$ $2, \pm 5 / 2, \pm 3 / 2$ and $\pm 1 / 2$, are evenly separated by approximately $2 / 3 \xi$. This splitting characterises the magnetic anisotropy barrier to the slow magnetic relaxation observed in $\mathrm{Li}_{2}\left(\mathrm{Li}_{0.985^{-}}\right.$ $\left.\mathrm{Fe}_{0.015}\right) \mathrm{N}$, Fig. 6b. At sufficiently low temperature only the $M_{\mathrm{J}}=$ $\pm 7 / 2$ Kramers doublet is populated. The $4.5 \mathrm{~K} \mathrm{~L}_{2,3}$-edge transitions hence emanate exclusively from the $M_{\mathrm{J}}= \pm 7 / 2$ doublet. To evaluate the magnetic anisotropy barrier precisely, temperature dependent $\mathrm{L}_{2,3}$-XAS measurements were performed. We find the strong selection rules of $\mathrm{L}_{2,3}$-edge XAS makes the technique particularly sensitive to the population of $M_{\mathrm{J}}$ states. Therefore, via a series of measurements from 4.5 to $400 \mathrm{~K}$ the thermal population of $M_{\mathrm{J}}$ excited states can be experimentally deduced from changes in the line shape of the $\mathrm{L}_{3}$-edge spectrum. The temperature dependence is most clearly identified through the relative peak intensity for Peak $1\left(P_{1}\right), E=706.1 \mathrm{eV}$ versus Peak 2 $\left(P_{2}\right), E=707.3 \mathrm{eV}$ at the $\mathrm{L}_{3}$-edge, Fig. 7. Modelling the temperature dependent ratio of $P_{1}$ and $P_{2}$ through Maxwell-Boltzmann statistics the thermal population of the excited states can be achieved through the equation:

$$
\frac{P_{1}}{P_{2}}=A \frac{\exp \left(-\frac{E_{7 / 2}}{k_{\mathrm{B}} T}\right)}{\sum_{i=M_{\mathrm{J}}} \exp \left(-\frac{E_{\mathrm{i}}}{k_{\mathrm{B}} T}\right)}+c
$$

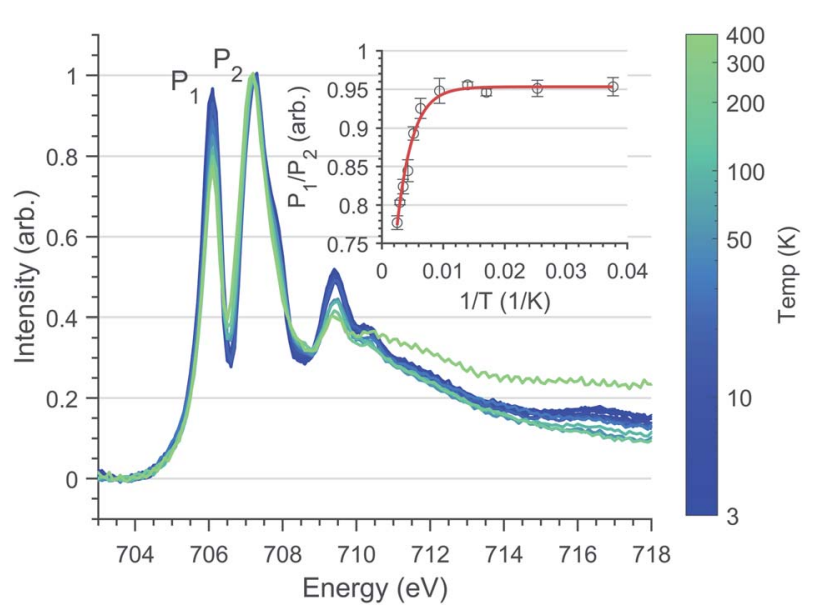

Fig. 7 Fe $\mathrm{L}_{3}$ temperature dependence spectra of $\mathrm{Li}_{2}\left(\mathrm{Li}_{0.98} \mathrm{Fe}_{0.02}\right) \mathrm{N}$ normalised through $P_{2}$ intensity. (Inlay) Least-squares fit of Eqn.(1) to $L_{3}$ peak ratio with respect to the inverse absolute temperature. Error bars represent standard deviation of repeat measurements. 
where $E_{i}$ represents the energy of the four $M_{\mathrm{J}} \pm 7 / 2, \pm 5 / 2, \pm 3 / 2$ and $\pm 1 / 2$ states (each evenly separated by $2 / 3 \xi$ ), $k_{\mathrm{B}}$ is the Boltzmann constant and $A$ and $c$ are multiplicative and scaling factors. The inlay of Fig. 7 shows $\mathrm{L}_{3}$-edge peak ratio $\left(P_{1} / P_{2}\right)$ versus inverse absolute temperature $(1 / T)$ for $\mathrm{Li}_{2}\left(\mathrm{Li}_{1-x} \mathrm{Fe}_{x}\right) \mathrm{N}$. Fitting to eqn (1) gives $\xi=52.2 \pm 4.97 \mathrm{meV}\left(421 \pm 40.08 \mathrm{~cm}^{-1}\right)$, significantly greater than the atomic value for $\mathrm{Fe}^{\mathrm{I}}$ of $44.8 \mathrm{meV}{ }^{6}$ Typically, the free ion spin-orbit coupling parameter represents the upper limit for spin-orbit coupling, where bonding leads to only decrease $\xi$. However, atomic spin-orbit coupling is strongly dependent on electron configuration, particularly on the number of $3 \mathrm{~d}$ electrons.$^{46}$ For instance, the $3 \mathrm{~d}$ atomic spin-orbit coupling for a $3 \mathrm{~d}^{6} 4 \mathrm{~s}^{1}$ configuration is $\xi_{3 \mathrm{~d}}=51 \mathrm{meV}$, approximately $6 \mathrm{meV}$ greater than the value for a $3 \mathrm{~d}^{7}$ configuration. ${ }^{47}$ Therefore, we propose that the measured value of $\xi$ is greater than the $3 d^{7}$ atomic value due to strong $4 s-3 d_{z^{2}}$ mixing. Previously reported measurements of magnetic relaxation for $\mathrm{Li}_{2}(-$ $\left.\mathrm{Li}_{1-x} \mathrm{Fe}_{x}\right) \mathrm{N}$ at low doping concentrations gave the effective energy barrier to magnetisation reversal ( $\left.U_{\text {eff }}\right)$ between 37.1 and $40.2 \mathrm{meV}$ (298.9 and $\left.324.6 \mathrm{~cm}^{-1}\right) .{ }^{12,19}$ This is close to $34.80 \pm$ $3.31 \mathrm{meV}\left(280.7 \mathrm{~cm}^{-1}\right)$ the energy splitting between the ground $M_{\mathrm{J}}= \pm 7 / 2$ and first excited $\pm 5 / 2$ doublet determined from our variable temperature $\mathrm{L}_{2,3}$-edge XAS analysis. To our knowledge the application of variable temperature $\mathrm{L}_{3}$-edge XAS has not been previously reported. Therefore, we performed supporting calculations into the origin of this effect. This enabled us to confirm the same temperature dependence in the simulated spectra and test the validity of our fitting method (Fig. S7 $\dagger$ ). Furthermore, to identify the origin of the temperature dependence Fig. S8† shows the calculated $\mathrm{L}_{2,3}$-edge XAS spectra associated with each thermally populated Kramer's doublet of the ground-state $J=7 / 2$ manifold. The calculations identify the individual intensity contributions to $P_{1}$ and $P_{2}$ for each $M_{\mathrm{J}}$ doublet.

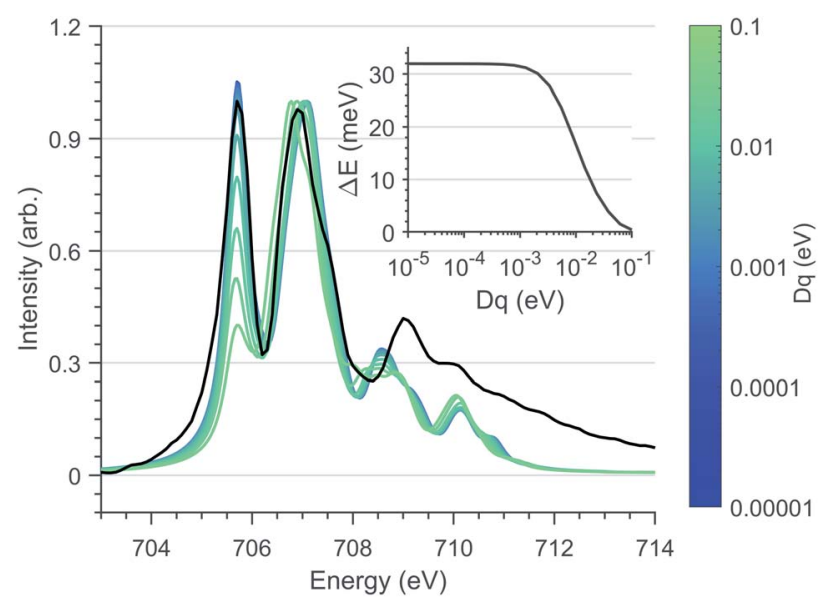

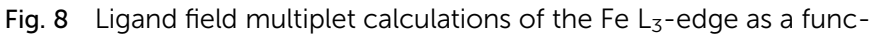
tion of $D_{\mathrm{q}}$ splitting, normalised through second peak intensity. The $D_{\mathrm{t}}$ and $D_{\mathrm{s}}$ crystal field and spin-orbit coupling parameters are fixed to the optimised vales used in Fig. 6a. (Black) Experimental spectrum of $\mathrm{Li}_{2}\left(\mathrm{Li}_{0.985} \mathrm{Fe}_{0.015}\right) \mathrm{N}$. (Inlay) Energy separation, $\Delta E$ of $M_{\mathrm{J}} \pm 7 / 2$ and $\pm 5 / 2$ states with respect to $D_{\mathrm{q}}$.
Since first-order spin-orbit coupling in $\mathrm{Li}_{2}\left(\mathrm{Li}_{1-x} \mathrm{Fe}_{x}\right) \mathrm{N}$ is a manifestation of an odd electron count within the $\mathrm{E}_{2 \mathrm{~g}}$ orbitals, the relationship between non-linearity due to $\mathrm{N}-\mathrm{Fe}-\mathrm{N}$ bending and the magnetic anisotropy barrier can be explored through the introduction of a $D_{\mathrm{q}}$ crystal field parameter. Fig. 8 shows the effect of including a non-zero $D_{\mathrm{q}}$ energy on the simulated $\mathrm{Fe}_{3_{3}}$ edge. To maintain the measured anisotropy energy of $\mathrm{Li}_{2}(-$ $\left.\mathrm{Li}_{0.985} \mathrm{Fe}_{0.015}\right) \mathrm{N}$, the magnitude of $D_{\mathrm{q}}$ must be less than $1 \mathrm{meV}$. This result supports our angular dependent K-edge XANES analysis, demonstrating the strict $\mathrm{N}-\mathrm{Fe}-\mathrm{N}$ linearity imposed within the $\alpha-\mathrm{Li}_{3} \mathrm{~N}$ matrix.

\section{Conclusion and outlook}

We have characterised the local geometric and electronic structure of Fe dopant sites in $\mathrm{Li}_{2}\left(\mathrm{Li}_{1-x} \mathrm{Fe}_{x}\right) \mathrm{N}$ via $\mathrm{K}$-edge XANES and EXAFS, $\mathrm{L}_{2,3}$-edge XAS and K $\beta$ XES as a function of $x$, with particular attention to low values of $x$, where Fe sites are sufficiently isolated and hence perform as single ion magnets. The complementary use of element specific X-ray spectroscopy techniques unambiguously answers a multitude of questions that had limited quantitative understanding of this system. $\mathrm{K} \beta$ XES analysis rules out previous arguments ${ }^{\mathbf{2 0}}$ for a divalent subspecies in $\mathrm{Li}_{2}\left(\mathrm{Li}_{1-x} \mathrm{Fe}_{x}\right) \mathrm{N}$ at low $x$ concentration. EXAFS analysis shows no evidence of preferential Fe clustering at low dopant concentrations. $\mathrm{L}_{2,3}$-edge XAS measurements in conjunction with ligand field multiplet simulations conclude Fe sites are monovalent with a ${ }^{4} D_{7 / 2}$ ground state of ${ }^{4} E$ symmetry resultant from a $\mathrm{a}_{1 \mathrm{~g}}{ }^{2} \mathrm{e}_{2 \mathrm{~g}}{ }^{3} \mathrm{e}_{1 \mathrm{~g}}{ }^{2}$ configuration. The energetic order of the $3 \mathrm{~d}$ orbitals is affected by strong $4 \mathrm{~s}-3 \mathrm{~d}_{z^{2}}$ mixing that results in a fully occupied $3 \mathrm{~d}_{z^{2}}$ at lowest energy. The strong influence of $4 \mathrm{~s}-3 \mathrm{~d}_{z^{2}}$ mixing in reducing the destabilisation of $3 \mathrm{~d} \sigma$ antibonding has long been reasoned by DFT and more recently by quantum chemistry calculations. ${ }^{6,48}$ It is shown that $\mathrm{L}_{2,3}$-edge XAS enables experimental quantification of $3 \mathrm{~d}_{z^{2}}$ energy reduction. The large $3 \mathrm{~d}_{z^{2}}$ energy reduction contributes to raising the anisotropy barrier in $\mathrm{Li}_{2}\left(\mathrm{Li}_{1-x} \mathrm{Fe}_{x}\right) \mathrm{N}$, and is much greater than values calculated for other linear monovalent SIMs, including the first two coordinate complex, $\left[\mathrm{Fe}\left(\mathrm{C}\left(\mathrm{SiMe}_{3}\right)_{3}\right)_{2}\right]^{-} .{ }^{6}$ Focusing then on low concentration $\mathrm{Li}_{2}\left(\mathrm{Li}_{1-x} \mathrm{Fe}_{x}\right) \mathrm{N}$, variable temperature $\mathrm{L}_{3}$-edge XAS measurements from 4.5 to $400 \mathrm{~K}$ enabled quantification of the magnetic anisotropy barrier to slow magnetic relaxation. Analysis of variable temperature $\mathrm{L}_{3}$-edge XAS enables determination of the ground state $J=7 / 2$ energy splittings. The splitting between the ground $M_{\mathrm{J}}= \pm 7 / 2$ doublet and first excited $M_{\mathrm{J}}= \pm 5 / 2$ doublet is $34.80 \pm 3.31 \mathrm{meV}\left(280.7 \mathrm{~cm}^{-1}\right)$, this value is consistent with reported $U_{\text {eff }}$ values obtained from magnetic relaxation measurements (37.1 and $40.2 \mathrm{meV}$ (298.9 and $\left.324.6 \mathrm{~cm}^{-1}\right)^{\mathbf{1 2 , 1 9}}$ ) identifying that magnetisation reversal manifests via this through barrier process. The $U_{\text {eff }}$ is larger than reported values for other linear Fe SIMs, including $\left[\mathrm{Fe}\left(\mathrm{C}\left(\mathrm{SiMe}_{3}\right)_{3}\right)_{2}\right]^{-}\left(U_{\text {eff }}=22.4 \mathrm{meV}, 181 \mathrm{~cm}^{-1}\right){ }^{6}$ but is less than the value recently reported for a linear Co complex $\mathrm{Co}^{\mathrm{II}}\left(\mathrm{C}\left(\mathrm{SiMe}_{2} \mathrm{ONaph}\right)_{3}\right)_{2}\left(55.8 \mathrm{meV}, 450 \mathrm{~cm}^{-1}\right)^{4}$ and lanthanide SIMs which can exceed $150 \mathrm{meV} .{ }^{49}$ Despite the unexceptional $U_{\text {eff }}$ energy for $\mathrm{Li}_{2}\left(\mathrm{Li}_{1-x} \mathrm{Fe}_{x}\right) \mathrm{N}$, the relaxation time at low temperatures certainly is exceptional $\tau=\sim 10^{7} \mathrm{~S}$ (ref. 19) in 
comparison with other linear SIMs where $\tau$ is within a range of seconds and less.

To further understand the origin of the unusually long $\mathrm{Li}_{2}\left(\mathrm{Li}_{1-x} \mathrm{Fe}_{x}\right) \mathrm{N}$ relaxation time, we have analysed the geometric structure and coordination symmetry around Fe dopant sites. EXAFS analysis find both Fe-N bond lengths as 1.873(7) $\AA$, which is exceptionally short for two-coordinate $\mathrm{Fe}^{\mathrm{I}}$. The shortness of the Fe- $\mathrm{N}$ bonds suggests strong Fe-N $\pi$ bonding, facilitated by the $D_{6 \mathrm{~h}}$ point symmetry providing equal N $2 \mathrm{p} \pi$ mixing into both $3 \mathrm{~d}_{x z}$ and $3 \mathrm{~d}_{y z}$ orbitals. ${ }^{50}$ Further evidence of this is observed via strong satellite intensities present in the $\mathrm{L}_{2,3}$-edge XAS spectra. The $\mathrm{N}-\mathrm{Fe}-\mathrm{N}$ angle is analysed by $\mathrm{K}$-edge XANES through single-crystal angular dependence of an intense, low energy, $7113 \mathrm{eV}$ peak. A ligand field interpretation is backed up by DFT calculations, assigning the transition as being associated with unoccupied $4 \mathrm{p}_{x, y}$ orbitals, from which it is deduced that the $\mathrm{N}-\mathrm{Fe}-\mathrm{N}$ bonding does not deviate from linear. This conclusion is supported by ligand field multiplet simulations that indicate that $D_{\mathrm{q}}$ induced degeneracy breaking of $3 \mathrm{~d}_{x y}$ and $3 \mathrm{~d}_{x^{2}-y^{2}}$ cannot exceed $1 \mathrm{meV}$ for the measured energy reversal barrier to be maintained.

Together the X-ray spectroscopy results identify $\mathrm{Li}_{2}\left(\mathrm{Li}_{1-x} \mathrm{Fe}_{x}\right)$ $\mathrm{N}$ as an ideal model system clean of stoichiometric vacancies where Fe sites are geometrically equivalent. The doping of $\mathrm{Fe}$ ions into the lithium nitride host matrix enables control of inter-SIM distances, from which dipolar fields can be minimised. The introduction of Fe sites displace Li ions at $2 c$ positions causing a local bond contraction of 0.062(7) A with respect to the equivalent $\mathrm{Li}-\mathrm{N}$ bond. The linear $\mathrm{N}-\mathrm{Fe}-\mathrm{N}$ core is supported through $3 \mathrm{~d}_{x z, y z}-\mathrm{N} \pi$ mixing and indirectly by the hexagonal lithium nitride lattice, that acts to drive bond shortening and rigorous linearity, in a similar but more direct way than dispersion force stabilisation observed in other linear molecular complexes, including $\mathrm{Fe}\left[\mathrm{N}\left(\mathrm{SiMe}_{3}\right) \mathrm{Dipp}\right]_{2} \cdot{ }^{38}$

Previous theoretical studies have identified the crucial influence of reduced symmetry and Renner-Teller vibronic coupling on the magnetic relaxation time in two coordinate $\mathrm{Fe}$ SIMs. ${ }^{51}$ It is proposed that the combination of a short $\mathrm{Fe}-\mathrm{N}$ bond, related strong $3 \mathrm{~d} \pi$ bonding, and high point symmetry imposed by the hexagonal lithium nitride lattice contribute to suppress vibronic effects, resulting in increased magnetic relaxation times with respect to other linear SIMs. The high point symmetry of the solid-state host lattice exhibit less disorder with respect to large inorganic coordination complexes. The high symmetry of the crystal host lattice and geometric equivalence of Fe dopant sites, result in a very low propensity for dislocation-induced strain type variations in local symmetry and easy axis directions, consistent with the extreme field dependence reported in $\mathrm{Li}_{2}\left(\mathrm{Li}_{1-x} \mathrm{Fe}_{x}\right) \mathrm{N} .^{13,19}$

The quantification of electronic structure reported here provides insights relevant for the advance of high performance magnets free from rare-earth metals. The extraordinary electronic and magnetic properties of $\mathrm{Li}_{2}\left(\mathrm{Li}_{1-x} \mathrm{Fe}_{x}\right) \mathrm{N}$, highlights the potential of doping paramagnetic ions within high symmetry solid-state lattices. Another area of potential relevance is nanoscale information storage for which there is currently considerable effort devoted to depositing coordination complexes with
SIM properties on surfaces. ${ }^{52,53}$ An even distribution of SIM dopant sites within a high symmetry host lattice crystal or thin film ${ }^{54}$ offers an interesting alternative method, with additional degrees of freedom for controlling local symmetry and lattice phonon dispersion.

\section{Conflicts of interest}

There are no conflicts to declare.

\section{Acknowledgements}

We acknowledge Diamond Light Source for experimental time for the following proposals; SI21117 and MM23982 at I10BLADE and SP20632 at I20-scanning. Use of the Stanford Synchrotron Radiation Lightsource, SLAC National Accelerator Laboratory, is supported by the U.S. Department of Energy, Office of Science, Office of Basic Energy Sciences under Contract No. DE-AC02-76SF00515. This work was supported by the Deutsche Forschungsgemeinschaft (DFG, German Research Foundation) - Grant No. JE748/1. MLB acknowledges the support of the Royal Society of Chemistry (RM1802-4019). David Collison is gratefully acknowledged for stimulating discussions and comments.

\section{Notes and references}

1 A. Jesche, L. Ke, J. L. Jacobs, B. Harmon, R. S. Houk and P. C. Canfield, Phys. Rev. B: Condens. Matter Mater. Phys., 2015, 91, 180403.

2 A. Jesche and P. Canfield, Philos. Mag., 2014, 94, 2372-2402.

3 M. A. Zykin, P. E. Kazin and M. Jansen, Chem.-Eur. J., 2020, 26, 8834-8844.

4 P. C. Bunting, M. Atanasov, E. Damgaard-Møller, M. Perfetti, I. Crassee, M. Orlita, J. Overgaard, J. Van Slageren, F. Neese and J. R. Long, Science, 2018, 362, 7319.

5 C. G. Werncke, E. Suturina, P. C. Bunting, L. Vendier, J. R. Long, M. Atanasov, F. Neese, S. Sabo-Etienne and S. Bontemps, Chem.-Eur. J., 2016, 22, 1668-1674.

6 J. M. Zadrozny, D. J. Xiao, M. Atanasov, G. J. Long, F. Grandjean, F. Neese and J. R. Long, Nat. Chem., 2013, 5, 577-581.

7 J. M. Zadrozny, D. J. Xiao, J. R. Long, M. Atanasov, F. Neese, F. Grandjean and G. J. Long, Inorg. Chem., 2013, 52, 1312313131.

8 M. K. Thomsen, A. Nyvang, J. P. Walsh, P. C. Bunting, J. R. Long, F. Neese, M. Atanasov, A. Genoni and J. Overgaard, Inorg. Chem., 2019, 58, 3211-3218.

9 P. P. Power, Comments Inorg. Chem., 2012, 8, 177-202.

10 C. J. Pollock, M. U. Delgado-Jaime, M. Atanasov, F. Neese and S. Debeer, J. Am. Chem. Soc., 2014, 136, 9453-9463.

11 F. de Groot and A. Kotani, Core level spectroscopy of solids, CRC Press, 2008, pp. 1-491.

12 A. Jesche, R. W. McCallum, S. Thimmaiah, J. L. Jacobs, V. Taufour, A. Kreyssig, R. S. Houk, S. L. Bud'Ko and P. C. Canfield, Nat. Commun., 2014, 5, 3333. 
13 M. Fix, A. Jesche, S. G. Jantz, S. A. Bräuninger, H. H. Klauss, R. S. Manna, I. M. Pietsch, H. A. Höppe and P. C. Canfield, Phys. Rev. B, 2018, 97, 064419.

14 P. Novák and F. R. Wagner, Phys. Rev. B: Condens. Matter Mater. Phys., 2002, 66, 1-6.

15 L. Ke and M. Van Schilfgaarde, Phys. Rev. B: Condens. Matter Mater. Phys., 2015, 92, 014423.

16 A. Yamada, S. Matsumoto and Y. Nakamura, J. Mater. Chem., 2011, 21, 10021-10025.

17 R. Niewa, Z. Hu and R. Kniep, Eur. J. Inorg. Chem., 2003, 2003(8), 1632-1634.

18 V. Ksenofontov, S. Reiman, M. Waldeck, R. Niewa, R. Kniep and P. Gütlich, Z. Anorg. Allg. Chem., 2003, 629, 1787-1794.

19 M. Fix, J. H. Atkinson, P. C. Canfield, E. Del Barco and A. Jesche, Phys. Rev. Lett., 2018, 120, 147202.

20 L. Xu, Z. Zangeneh, R. Yadav, S. Avdoshenko, J. Van Den Brink, A. Jesche and L. Hozoi, Nanoscale, 2017, 9, 1059610600.

21 S. Hayama, G. Duller, J. P. Sutter, M. Amboage, R. Boada, A. Freeman, L. Keenan, B. Nutter, L. Cahill, P. Leicester, B. Kemp, N. Rubies and S. Diaz-Moreno, J. Synchrotron Radiat., 2018, 25, 1556-1564.

22 H. J. Beister, S. Haag, R. Kniep, K. Strössner and K. Syassen, Angew. Chem., Int. Ed. Engl., 1988, 27, 1101-1103.

23 B. Ravel and M. Newville, J. Synchrotron Radiat., 2005, 12, 537-541.

24 E. C. Wasinger, F. M. De Groot, B. Hedman, K. O. Hodgson and E. I. Solomon, J. Am. Chem. Soc., 2003, 125, 12894-12906.

25 M. W. Haverkort, M. Zwierzycki and O. K. Andersen, Phys. Rev. B: Condens. Matter Mater. Phys., 2012, 85, 165113.

26 M. Retegan, Crispy: v0.7.3, 2019, DOI: 10.5281/ zenodo.1008184.

27 P. Giannozzi, S. Baroni, N. Bonini, M. Calandra, R. Car, C. Cavazzoni, D. Ceresoli, G. L. Chiarotti, M. Cococcioni, I. Dabo, A. Dal Corso, S. De Gironcoli, S. Fabris, G. Fratesi, R. Gebauer, U. Gerstmann, C. Gougoussis, A. Kokalj, M. Lazzeri, L. Martin-Samos, N. Marzari, F. Mauri, R. Mazzarello, S. Paolini, A. Pasquarello, L. Paulatto, C. Sbraccia, S. Scandolo, G. Sclauzero, A. P. Seitsonen, A. Smogunov, P. Umari and R. M. Wentzcovitch, J. Phys.: Condens. Matter, 2009, 21, 395502.

28 S. J. Clark, M. D. Segall, C. J. Pickard, P. J. Hasnip, M. I. Probert, K. Refson and M. C. Payne, Z. Kristallogr. Cryst. Mater., 2005, 220, 567-570.

29 J. P. Perdew, K. Burke and M. Ernzerhof, Phys. Rev. Lett., 1996, 77, 3865-3868.

30 A. Dal Corso, Comput. Mater. Sci., 2014, 95, 337-350.

31 S. P. Gao, C. J. Pickard, M. C. Payne, J. Zhu and J. Yuan, Phys. Rev. B: Condens. Matter Mater. Phys., 2008, 77, 115122.

32 V. I. Anisimov, J. Zaanen and O. K. Andersen, Phys. Rev. B: Condens. Matter Mater. Phys., 1991, 44, 943-954.

33 M. Cococcioni and S. De Gironcoli, Phys. Rev. B: Condens. Matter Mater. Phys., 2005, 71, 035105.

34 V. P. Antropov and V. N. Antonov, Phys. Rev. B: Condens. Matter Mater. Phys., 2014, 90, 94406.

35 J. Klatyk and R. Kniep, Z. Kristallogr. NCS, 1999, 214, 447448.
36 C. Gunnar Werncke, P. C. Bunting, C. Duhayon, J. R. Long, S. Bontemps and S. Sabo-Etienne, Angew. Chem., Int. Ed., 2015, 54, 245-248.

37 C. Y. Lin, J. C. Fettinger, F. Grandjean, G. J. Long and P. P. Power, Inorg. Chem., 2014, 53, 9400-9406.

38 C. Y. Lin, J. D. Guo, J. C. Fettinger, S. Nagase, F. Grandjean, G. J. Long, N. F. Chilton and P. P. Power, Inorg. Chem., 2013, 52, 13584-13593.

39 D. Muller-Bouvet, J. P. Pereira-Ramos, S. Bach, P. Willmann and A. Michalowicz, Inorg. Chem., 2014, 53, 6127-6131.

40 J. Klatyk, W. Schnelle, F. R. Wagner, R. Niewa, P. Novák, R. Kniep, M. Waldeck, V. Ksenofontov and P. Gütlich, Phys. Rev. Lett., 2002, 88, 2072021-2072024.

41 S. D. Kelly, D. Hesterberg and B. Ravel, Methods of Soil Analysis Part 5 - Mineralogical Methods, Soil Science Society of America, 2008, ch. 14, pp. 387-463.

42 T. E. Westre, P. Kennepohl, J. G. DeWitt, B. Hedman, K. O. Hodgson and E. I. Solomon, J. Am. Chem. Soc., 1997, 119, 6297-6314.

43 R. Niewa, Z. Hu and R. Kniep, Eur. J. Inorg. Chem., 2003, 2003, 1632-1634.

44 L. S. Kau, D. J. Spira-Solomon, J. E. Penner-Hahn, K. O. Hodgson and E. I. Solomon, J. Am. Chem. Soc., 1987, 109, 6433-6442.

45 W. Zhang, R. Alonso-Mori, U. Bergmann, C. Bressler, M. Chollet, A. Galler, W. Gawelda, R. G. Hadt, R. W. Hartsock, T. Kroll, K. S. Kjær, K. Kubiek, H. T. Lemke, H. W. Liang, D. A. Meyer, M. M. Nielsen, C. Purser, J. S. Robinson, E. I. Solomon, Z. Sun, D. Sokaras, T. B. Van Driel, G. Vankó, T. C. Weng, D. Zhu and K. J. Gaffney, Nature, 2014, 509, 345-348.

46 P. H. Rieger, J. Magn. Reson., 1997, 124, 140-146.

47 R. D. Cowan, The Theory of Atomic Structure and Spectra, University of California Press, 1981, p. 731.

48 S. G. Wang and W. H. Schwarz, J. Chem. Phys., 1998, 109, 7252-7262.

49 C. A. Goodwin, F. Ortu, D. Reta, N. F. Chilton and D. P. Mills, Nature, 2017, 548, 439-442.

50 W. M. Reiff, C. E. Schulz, M. H. Whangbo, J. I. Seo, Y. S. Lee, G. R. Potratz, C. W. Spicer and G. S. Girolami, J. Am. Chem. Soc., 2009, 131, 404-405.

51 M. Atanasov, J. M. Zadrozny, J. R. Long and F. Neese, Chem. Sci., 2013, 4, 139-156.

52 V. E. Campbell, M. Tonelli, I. Cimatti, J. B. Moussy, L. Tortech, Y. J. Dappe, E. Rivière, R. Guillot, S. Delprat, R. Mattana, P. Seneor, P. Ohresser, F. Choueikani, E. Otero, F. Koprowiak, V. G. Chilkuri, N. Suaud, N. Guihéry, A. Galtayries, F. Miserque, M. A. Arrio, P. Sainctavit and T. Mallah, Nat. Commun., 2016, 7, 13646.

53 M. Mannini, F. Pineider, C. Danieli, F. Totti, L. Sorace, P. Sainctavit, M. A. Arrio, E. Otero, L. Joly, J. C. Cezar, A. Cornia and R. Sessoli, Nature, 2010, 468, 417-421.

54 Y. Li, Y. Sun, A. Pei, K. Chen, A. Vailionis, Y. Li, G. Zheng, J. Sun and Y. Cui, ACS Cent. Sci., 2018, 4, 97-104.

55 S. A. Bräuninger, A. Jesche, S. Kamusella, F. Seewald, M. Fix, R. Sarkar, A. A. Zvyagin and H.-H. Klauss, Phys. Rev. B, 2020, $102,054426$. 